\title{
PENGARUH VARIASI PENDINGIN TERHADAP KEKUATAN BENDING PADA PENGELASAN TEE JOINT EQUALIZER TYPE YORK TRAILER
}

\author{
Akhmad Syarief ${ }^{1)}$, Baramsyah ${ }^{2)}$ \\ 1,2Program Studi Teknik Mesin, \\ Fakultas Teknik Universitas Lambung Mangkurat \\ JL. Akhmad Yani Km.36 Banjarbaru, Kalimantan Selatan,70714 \\ Telp. 0511-4772646, Fax 0511-4772646 \\ E-mail: baramsyah16@gmail.com
}

\begin{abstract}
In the present era of technological developments in the industrial world is growing and progressing. But in the industrial world can not be separated from the manufacturing process, especially in the field of welding, because welding has an important role in engineering or reparasi-raparasi associated with metal welding. And also a lot of welding is used in the field of design. The scope of welding use in construction is very wide including shipping industry, bridge, steel frame, heavy equipment, transportation facilities, pipeline and so forth. In the process of welding requires a person who is reliable or skilled in welding work, in order to produce good quality results. The highest value of bending stress is found on air cooling medium that is $2870,17 \mathrm{~N} / \mathrm{mm}^{2}$, And the lowest bending voltage value is in water cooling that is $2460,1 \mathrm{~N} / \mathrm{mm}^{2}$. The highest shear stress value is in air cooling medium ie 197.96 $\mathrm{N} / \mathrm{mm}^{2}$, and the lowest shear stress value is in water cooling that is $169.68 \mathrm{~N} / \mathrm{mm}^{2}$. The bending voltage value allowed is the highest in the air conditioning medium $2474.5 \mathrm{~N} / \mathrm{mm}^{2}$, And the lowest permissible bending stress value is found in water cooling of $2121 \mathrm{~N} / \mathrm{mm}^{2}$.
\end{abstract}

Keywords : Tee Joint, Cooling Media, Bending

\section{PENDAHULUAN}

Diera masa kini perkembangan teknologi didunia industri semakin berkembang dan semakin maju. Namun dalam dunia industri tidak lepas dari proses manufaktur khususnya dibidang pengelasan, karena pengelasan mempunyai peranan penting dalam rekayasa ataupun reparasi-raparasi yang berkaitan dengan pengelasan logam. Dan juga banyak pengelasan digunakan pada bidang rancang bangun. Lingkup penggunaan pengelasan dalam kontruksi sangat luas meliputi industri perkapalan, jembatan, rangka baja, alat berat, sarana trasportasi, pipa saluran dan lain sebagainya. Dalam proses pengelasan sangat memerlukan orang yang handal atau terampil dalam pekerjaan mengelas, agar dapat menghasilkan hasil yang berkualitas baik.

Masalah yang sering terjadi pada sambungan las adalah porositas yang disebabkan oleh elektroda yang tidak sesuai dan juga disebabkan oleh benda kerja yang kotor oleh air, minyak, cat dan kotoran-kotoran yang lain. Karena itulah dapat mengakibatkan kerusakan pada sambungan las terhadap benda kerja yang dilas.Adapun faktor-faktor yang mempengaruhi hasil pengelasan antara lain prosedur pengelasan, dimana suatu perencanaan untuk pelaksanaan, yang meliputi cara pembuatan konstruksi las yang sesuai perencanaan tersebut. Faktor dalam produksi pengelasan adalah jadwal pembuatan, proses pembuatan, alat dan bahan yang diperlukan, urutan persiapan pelaksanaan pengelasan. 
Disini peneliti mengambil atau mengangkat judul dari sebuah perusahaan PT. Muda Kreatif, perusahaan tersebut khususnya bergerak dibidang manufaktur seperti pengelasan dan juga pembubutan. Di perusahan tersebut menerima pembuatan dan juga reparasi yang datang dari perusahaan-perusahaan. Permintaan yang sering datang di PT. Muda Kreatif yaitu permintaan dari perusahaan pertambangan. Adapun produk atau reparasi yang dikerjakan di PT. Muda Kreatif antara lain, Pembuatan/ reparasi equalizer dan pin equalizer, Pembuatan poli-poli mesin, Reparasi gardan, Pembuatan roda gigi, Pembuatan/ reparasi velg, Perbaikan bucket, Pembuatan pinlock dump HD, Reparasi V-Stay.

Ada beberapa pengujian daerah las terbagi atas dua yaitu pengujian merusak dan pengujian tidak merusak benda kerja. Pada pengujian ini peneliti menggunakan pengujian merusak yaitu dengan uji bending. Jadi disini peneliti akan melakukan pengujian bending yang bertujuan untuk, mengetahui lebih kuat atau lebih baik yang mana antara pendinginan menggunakan air dan juga menggunakan udara.

\section{METODE PENELITIAN}

Metode yang digunakan adalah metode eksperimen menggunakan baja KS SS400, elektoda LB 52 (3,2 mm). Pembuatan Spesimen benda di Workshop Teknik Mesin ULM, pengujian benda spesimen di Lab Materaial UGM.

\section{Diagram Alir Penelitian}

Diagram alir dari penelitian ini ditunjukkan pada Gambar 1.

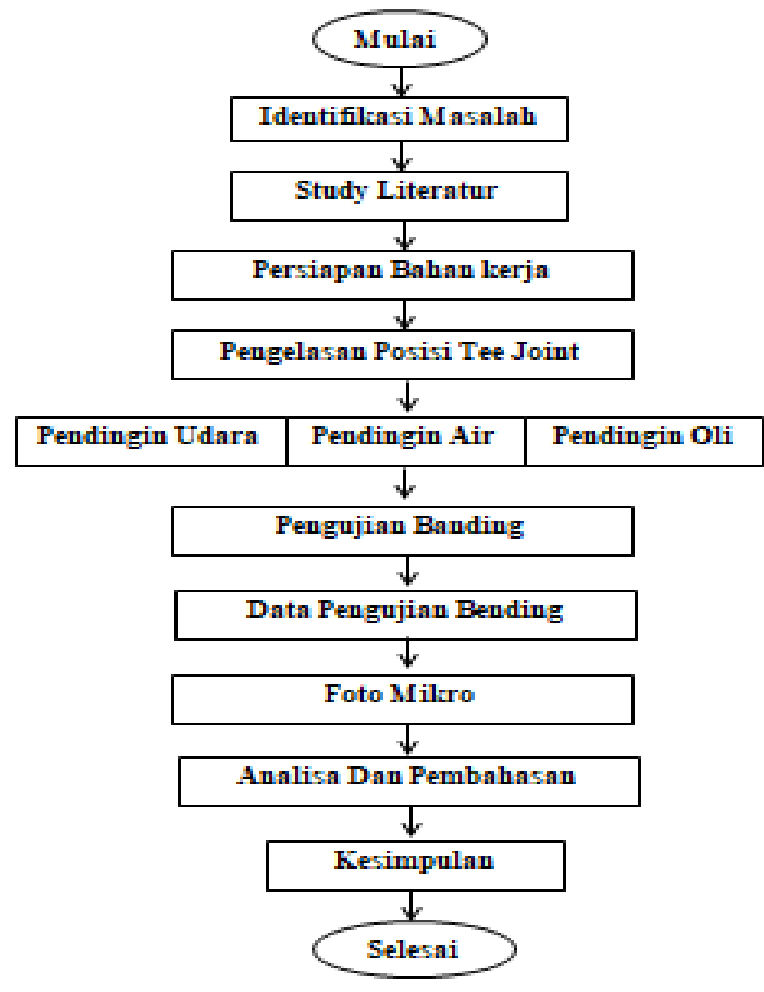

Gambar 1. Diagram Alir Penelitian 


\section{HASIL DAN PEMBAHASAN}

Data hasil pengujian bending tee joint lebih dapat di lihat pada Tabel 1.

Tabel 1. Data hasil pengujian

\begin{tabular}{|c|c|c|c|c|c|}
\hline \multirow{2}{*}{ No } & Spesimen & $\begin{array}{c}\text { Tebal } \\
(\mathrm{mm})\end{array}$ & $\begin{array}{c}\text { Lebar } \\
(\mathrm{mm})\end{array}$ & $\begin{array}{c}\text { Daya } \\
\text { Maksimal } \\
\left(\mathrm{N} / \mathrm{mm}^{2}\right)\end{array}$ & keterangan \\
\hline \multirow{3}{*}{1} & Pendingin udara 1 & 16 & 70 & 94000 & Retak \\
\cline { 2 - 6 } & Pendingin udara 2 & 16 & 70 & 98000 & Retak \\
\cline { 2 - 6 } & Pendingin udara 3 & 16 & 70 & 91000 & Retak \\
\hline \multirow{3}{*}{2} & Pendingin air 1 & 16 & 70 & 84000 & Retak \\
\cline { 2 - 6 } & Pendingin air 2 & 16 & 70 & 97000 & Retak \\
\cline { 2 - 7 } & Pendingin air 3 & 16 & 70 & 97000 & Retak \\
\hline \multirow{3}{*}{3} & Pendingin oli 1 & 16 & 70 & 94000 & Retak \\
\cline { 2 - 6 } & Pendingin oli 2 & 16 & 70 & 96000 & Retak \\
\cline { 2 - 6 } & Pendingin oli 3 & 16 & 70 & 92000 & Retak \\
\hline
\end{tabular}

Berikut data perhitungan pengujian bending tee joint dapat di lihat pada Tabel 2.

Tabel 2. Hasil perhitungan pengujian bending

\begin{tabular}{|c|c|c|c|c|}
\hline NO & Spesimen & $\begin{array}{l}\text { Tegangan bending } \\
\left(\mathrm{N} / \mathrm{mm}^{2}\right)\end{array}$ & $\begin{array}{c}\text { Tegangangeser } \\
\left(\mathrm{N} / \mathrm{mm}^{2}\right)\end{array}$ & $\begin{array}{c}\text { Tegangan } \\
\text { Bending yang } \\
\text { diizinkan } \\
\left(\mathrm{N} / \mathrm{mm}^{2}\right)\end{array}$ \\
\hline \multirow{3}{*}{1} & Pendingin udara 1 & 2752,9 & 189,88 & 2373,5 \\
\hline & Pendingin udara 2 & 2870,1 & 197,96 & 2474.5 \\
\hline & Pendingin udara 3 & 2665,1 & 183,82 & 2297.7 \\
\hline \multirow{3}{*}{2} & Pendingin air 1 & 2460,1 & 169,68 & 2121 \\
\hline & Pendingin air 2 & 2839,4 & 195,94 & 2449,2 \\
\hline & Pendingin air 3 & 2839.4 & 195,94 & 2449,2 \\
\hline \multirow{3}{*}{3} & Pendingin oli1 & 2752,9 & 189,88 & 2373,5 \\
\hline & Pendingin oli2 & 2810,7 & 193,92 & 2424 \\
\hline & Pendingin oli 3 & 2693,8 & 185,84 & 2323 \\
\hline
\end{tabular}




\section{Pengujian Tegangan Bending dan Tegangan Geser}

Tegangan bending pada spesimen uji dapat dilihat dalam Gambar 1.

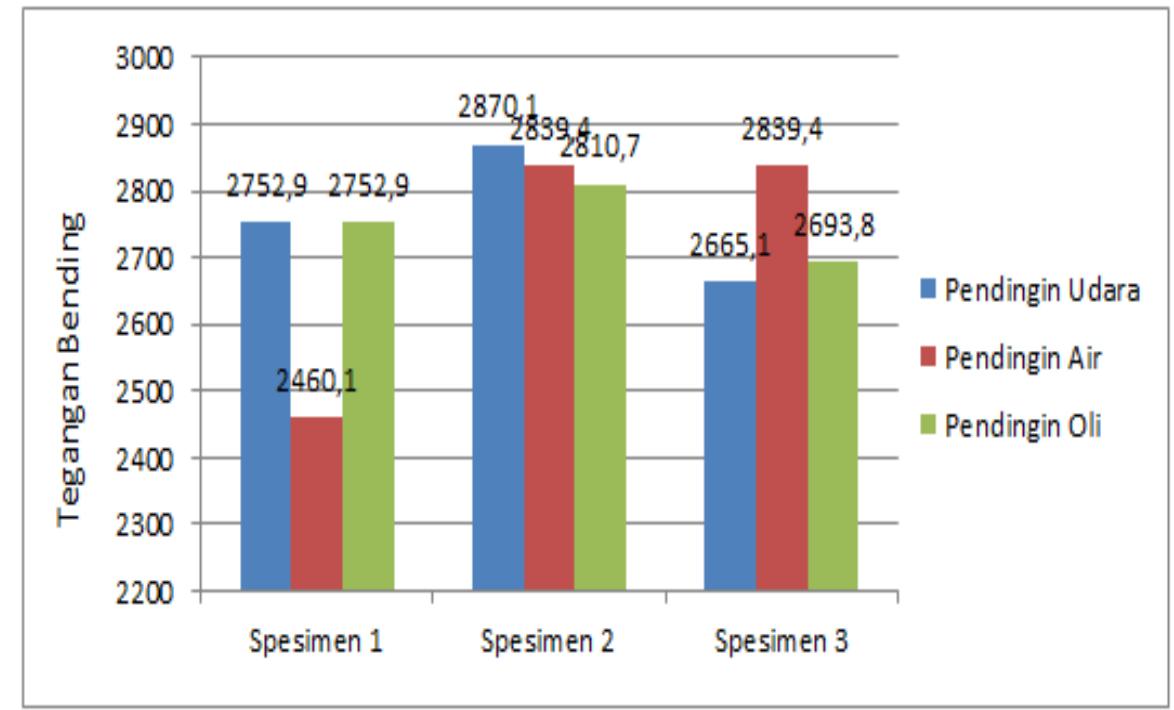

Gambar 1. Grafik Perbandingan Kekuatan Tegangan Bending (N/mm²)

Dari Gambar 1 dapat kita lihat nilai tegangan bending yang paling tinggi terdapat pada media pendingin udara yaitu $2870,17 \mathrm{~N} / \mathrm{mm}^{2}$, Dan nilai ketangguhan yang paling rendah terdapat pada pendinginan air yaitu $2460,1 \mathrm{~N} / \mathrm{mm}^{2}$.

Tegangan geser pada spesimen uji dapat dilihat dalam Gambar 2.

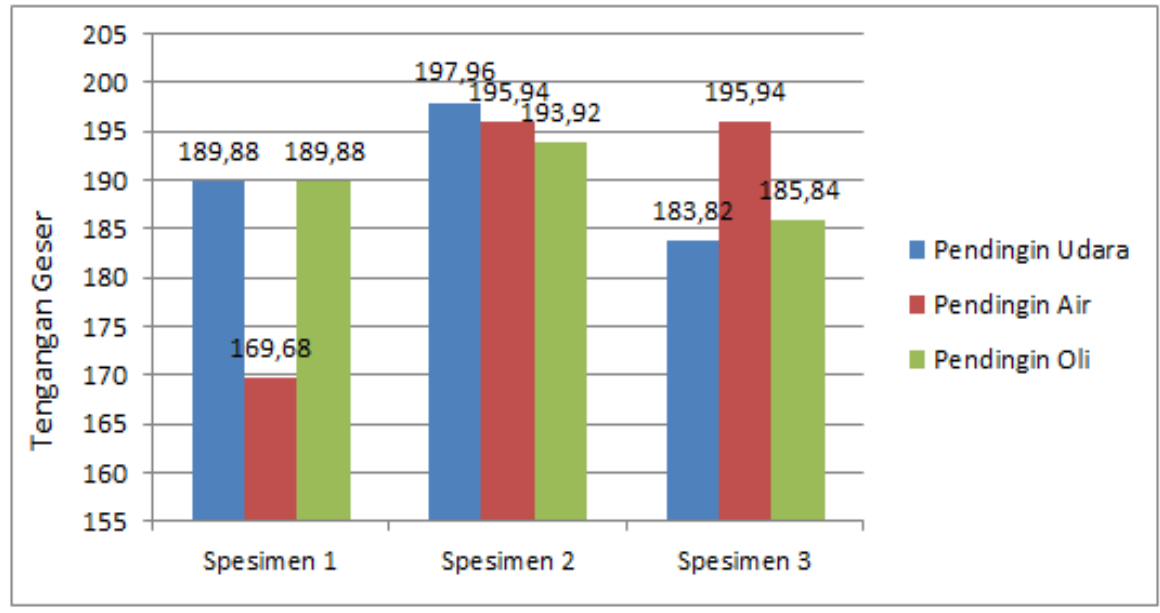

Gambar 2. Grafik Perbandingan Kekuatan Tegangan Geser (N/mm²)

Dari Gambar 2 dapat kita lihat nilai tegangan geser yang paling tinggi terdapat pada media pendingin udara yaitu $197,96 \mathrm{~N} / \mathrm{mm}^{2}$, Dan nilai ketangguhan yang paling rendah terdapat pada pendinginan air yaitu $169,68 \mathrm{~N} / \mathrm{mm}^{2}$. 
Tegangan bending yang di izinkan pada spesimen uji dapat dilihat dalam Gambar 3.

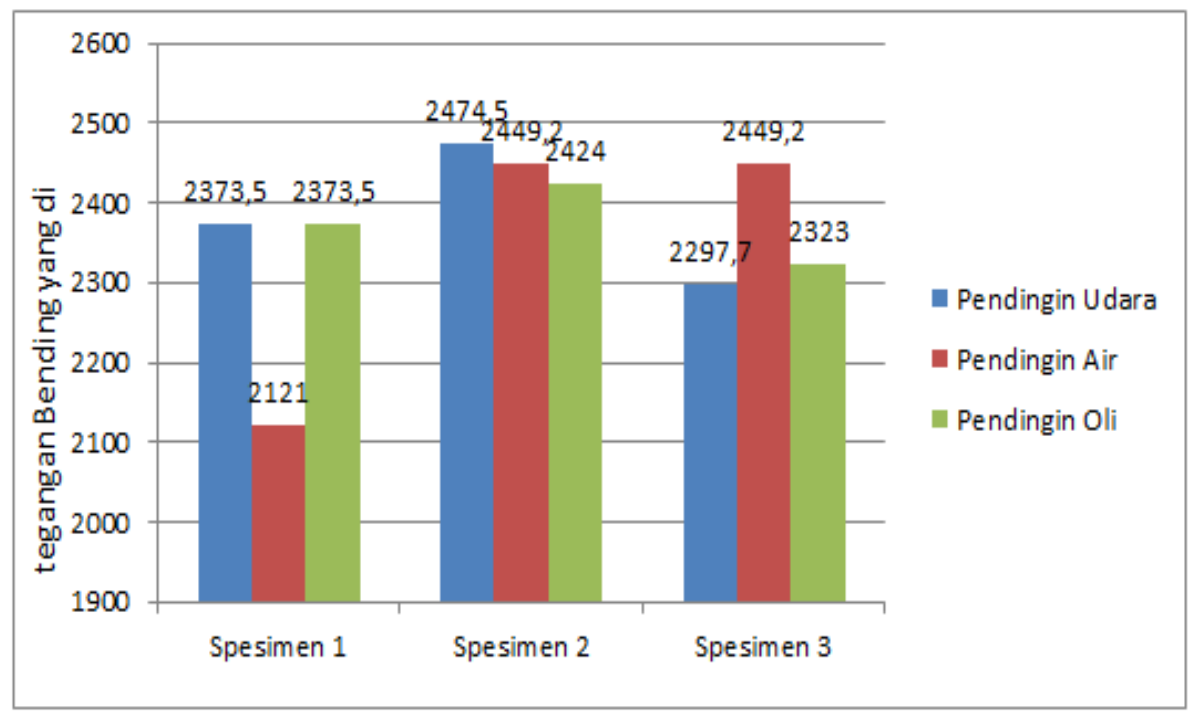

Gambar 3. Grafik Perbandingan Tegangan Bending Diizinkan (N/mm²)

Dari Gambar 3 dapat kita lihat nilai tegangan bending yang di izinkan yaitu yang paling tinggi terdapat pada media pendingin udara yaitu $2474,5 \mathrm{~N} / \mathrm{mm}^{2}$, Dan nilai ketangguhan yang paling rendah terdapat pada pendinginan air yaitu 2121 $\mathrm{N} / \mathrm{mm}^{2}$.

\section{Pengujian Struktur Mikro}

Pengujian struktur mikro di lakukan bertujuan agar dapat mengetahui susunan struktur logam pada bahan spesimen uji.

a. Foto mikro pada pendinginan udara dengan pembesaran 100X, 200X, dan 500x dapat dilihat dalam Gambar 4 sampai dengan Gambar 6.

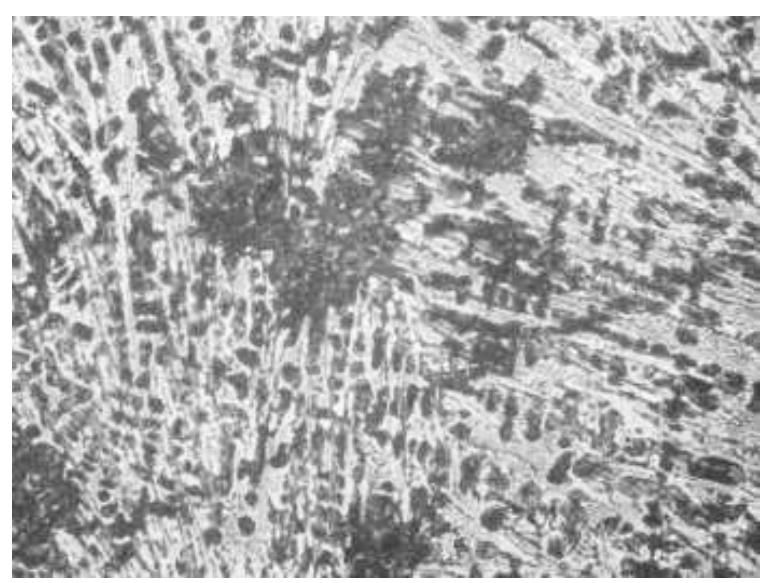

Gambar 4. Foto Mikro Untuk Pendinginan Udara Pembesaran 100X 


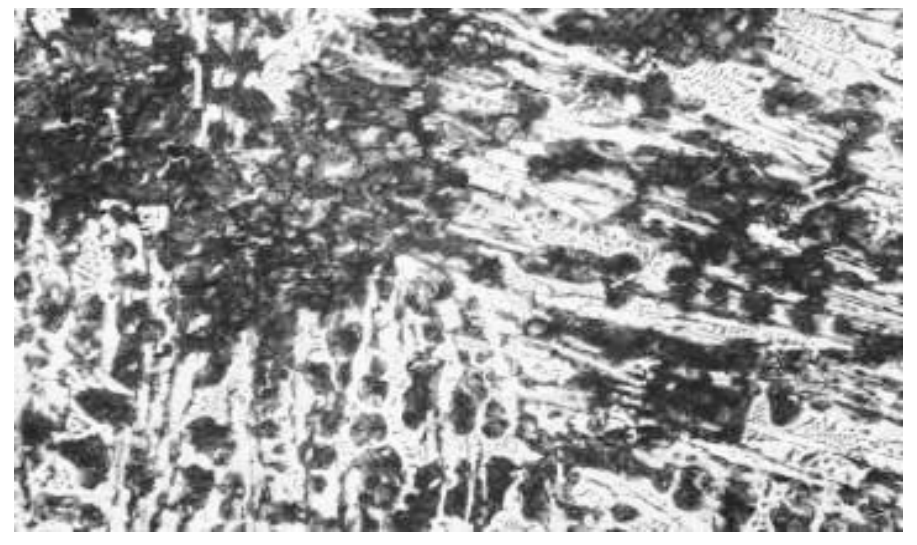

Gambar 5. Foto Mikro Untuk Pendinginan Udara Pembesaran 200X

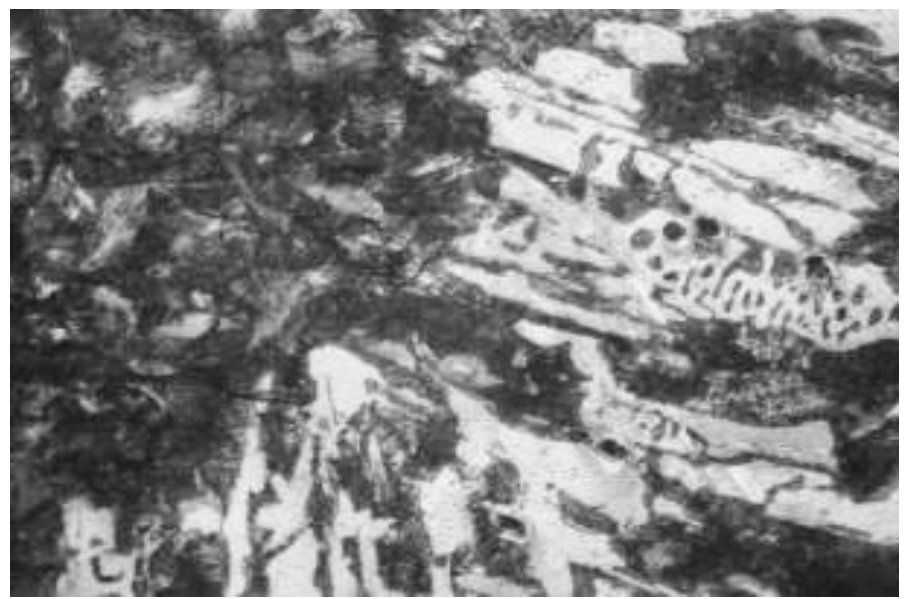

Gambar 6. Foto Mikro Untuk Pendinginan Udara Pembesaran 500X

b. Foto mikro pada spesimen pendinginan air dengan pembesaran 100X, 200X, 500X dapat dilihat dalam Gambar 7 sampai dengan Gambar 9.

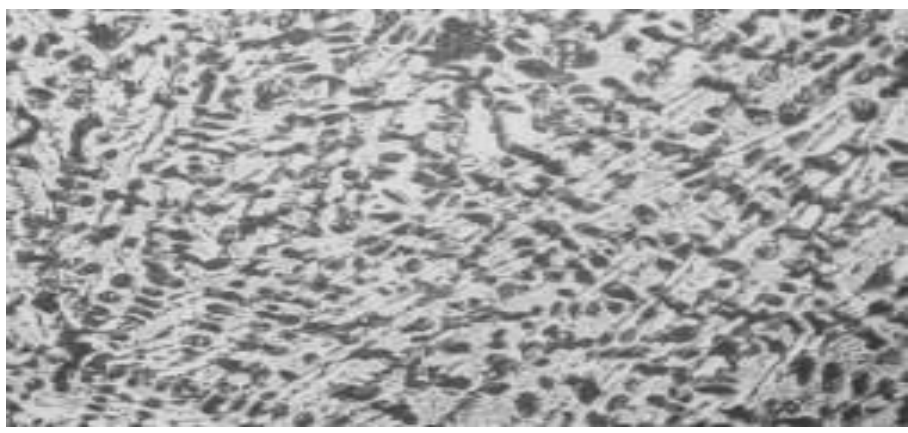

Gambar 7. Foto Mikro Untuk Pendinginan Air Pembesaran 100X 


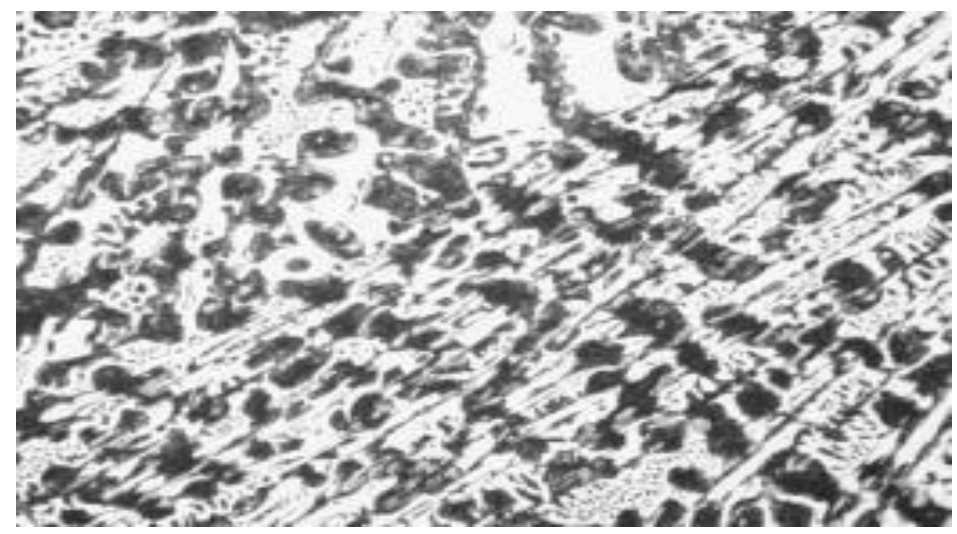

Gambar 8. Foto Mikro Untuk Pendinginan Air Pembesaran 200X

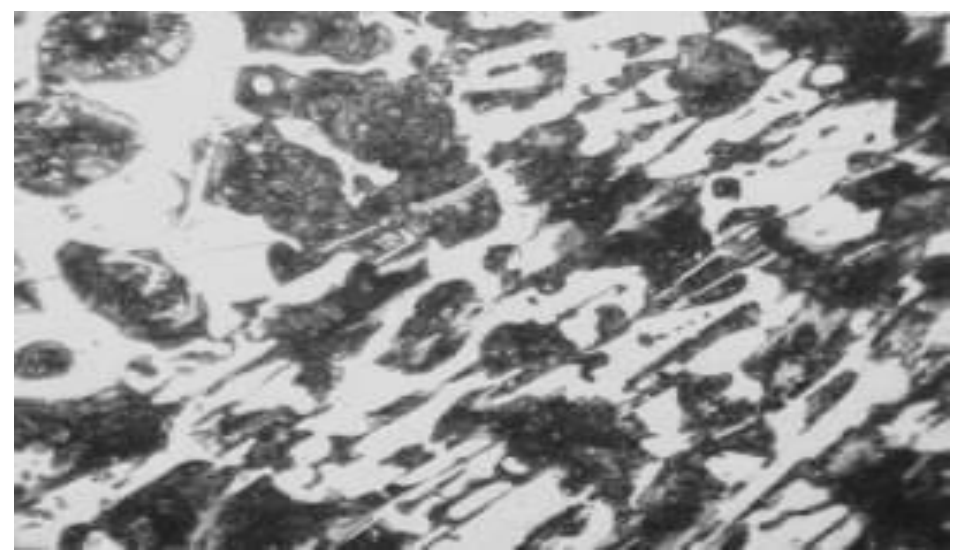

Gambar 9. Foto Mikro Untuk Pendinginan Air Pembesaran 500X

c. Foto mikro pada pendinginan oli pembesaran 100X, 200X, 500X dapat dilihat dalam Gambar 10 sampai dengan Gambar 12.

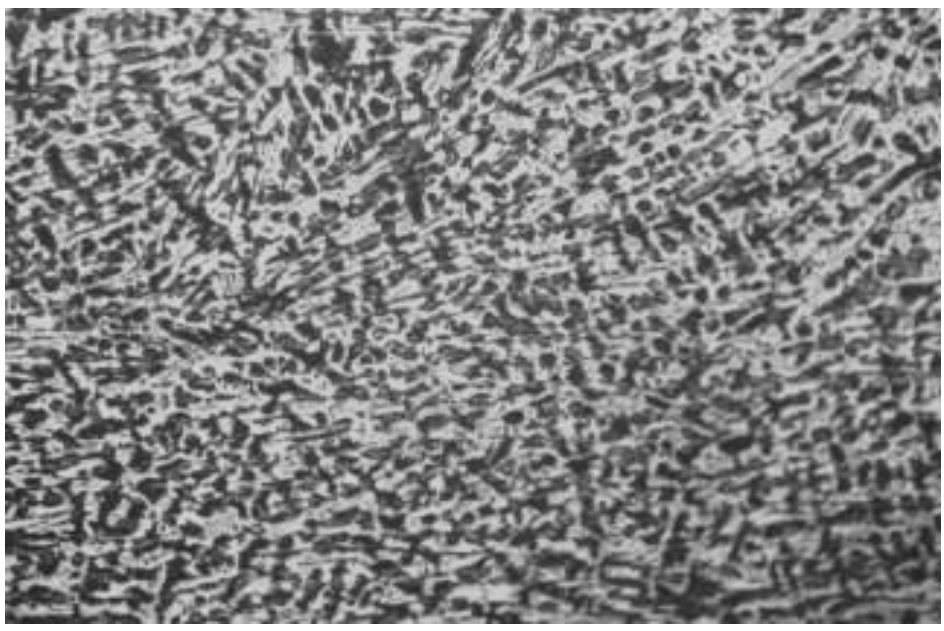

Gambar 10. Foto Mikro Pendinginan Oli Pembesaran 100X 


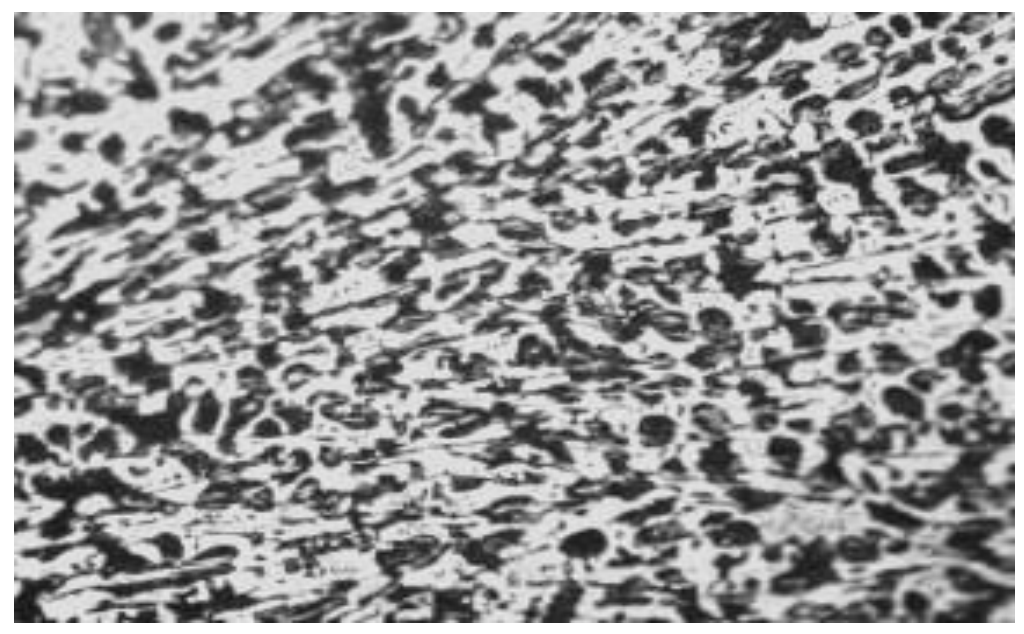

Gambar 11. Foto Mikro Pendinginan Oli Pembesaran 200X

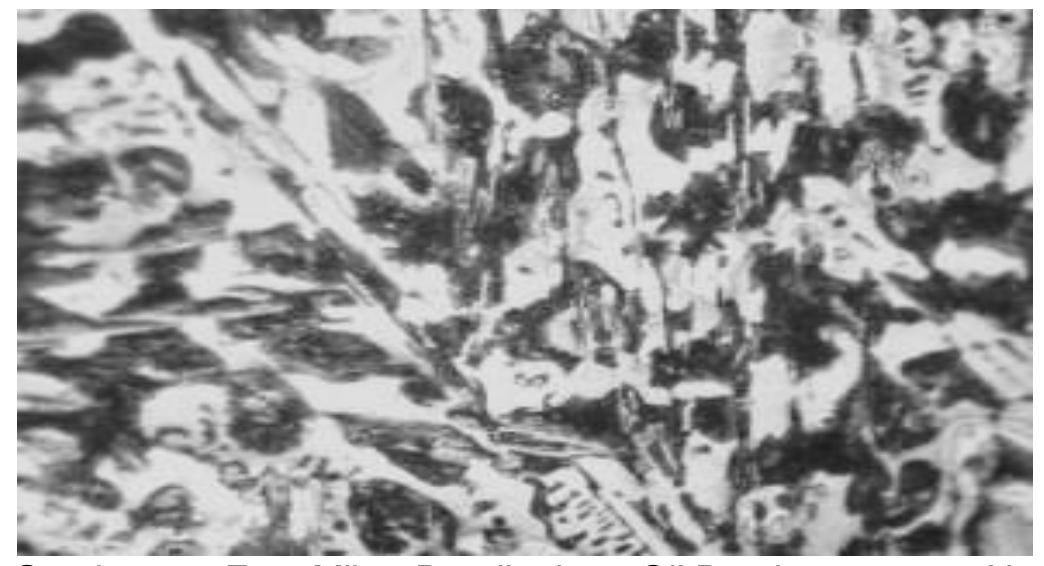

Gambar 12. Foto Mikro Pendinginan Oli Pembesaran 500X

Nilai untuk tegangan bending untuk spesimen pertama 2752,9 N/mm², spesimen kedua $2870,1 \mathrm{~N} / \mathrm{mm}^{2}$, dan spesimen ketiga $2665,1 \mathrm{~N} / \mathrm{mm}^{2}$. Nilai pada tegangan geser untuk spesimen pertama $189,88 \mathrm{~N} / \mathrm{mm}^{2}$, spesimen kedua $197,96 \mathrm{~N} / \mathrm{mm}^{2}$, dan spesimen ketiga $183,82 \mathrm{~N} / \mathrm{mm}^{2}$. dan untuk tegangan bending yang diizinkan dengan nilai untuk spesimen pertama $2373,5 \mathrm{~N} / \mathrm{mm}^{2}$, spesimen kedua $2474,5 \mathrm{~N} / \mathrm{mm}^{2}$ dan spesimen yang ketiga $2297,75 \mathrm{~N} / \mathrm{mm}^{2}$.

Nilai untuk tegangan bending untuk spesimen pertama $2460,1 \mathrm{~N} / \mathrm{mm}^{2}$, spesimen kedua $2839,4 \mathrm{~N} / \mathrm{mm}^{2}$, dan spesimen ketiga $2839,4 \mathrm{~N} / \mathrm{mm}^{2}$. Nilai pada tegangan geser untuk spesimen pertama 169,68 N/mm², spesimen kedua $195,94 \mathrm{~N} / \mathrm{mm}^{2}$, dan spesimen ketiga $195,94 \mathrm{~N} / \mathrm{mm}^{2}$. dan untuk tegangan bending yang diizinkan dengan nilai untuk spesimen pertama $2121 \mathrm{~N} / \mathrm{mm}^{2}$, spesimen kedua $2449,25 \mathrm{~N} / \mathrm{mm}^{2}$ dan spesimen yang ketiga $2449,25 \mathrm{~N} / \mathrm{mm}^{2}$.

Nilai untuk tegangan bending untuk spesimen pertama 2752,9 N/mm², spesimen kedua $2810,7 \mathrm{~N} / \mathrm{mm}^{2}$, dan spesimen ketiga $2693,8 \mathrm{~N} / \mathrm{mm}^{2}$. Nilai pada tegangan geser untuk spesimen pertama $189,88 \mathrm{~N} / \mathrm{mm}^{2}$, spesimen kedua $193,92 \mathrm{~N} / \mathrm{mm}^{2}$, dan spesimen ketiga $185,84 \mathrm{~N} / \mathrm{mm}^{2}$. dan untuk tegangan bending 
yang diizinkan dengan nilai untuk spesimen pertama $2373,5 \mathrm{~N} / \mathrm{mm}^{2}$, spesimen kedua $2474 \mathrm{~N} / \mathrm{mm}^{2}$ dan spesimen yang ketiga $2323 \mathrm{~N} / \mathrm{mm}^{2}$.

\section{KESIMPULAN}

Dari penelitian yang dilakukan dapat disimpulkan sebagai berikut :

1. Nilai tegangan bending yang paling tinggi terdapat pada media pendingin udara yaitu $2870,17 \mathrm{~N} / \mathrm{mm}^{2}$, Dan nilai tegangan bending yang paling rendah terdapat pada pendinginan air yaitu $2460,1 \mathrm{~N} / \mathrm{mm}^{2}$.

2. Nilai tegangan geser yang paling tinggi terdapat pada media pendingin udara yaitu $197,96 \mathrm{~N} / \mathrm{mm}^{2}$, Dan nilai tegangan geser yang paling rendah terdapat pada pendinginan air yaitu $169,68 \mathrm{~N} / \mathrm{mm}^{2}$.

3. Nilai tegangan bending yang di izinkan yaitu yang paling tinggi terdapat pada media pendingin udara yaitu $2474,5 \mathrm{~N} / \mathrm{mm}^{2}$, Dan nilai tegangan bending yang di izinkan yang paling rendah terdapat pada pendinginan air yaitu $2121 \mathrm{~N} / \mathrm{mm}^{2}$. 


\section{DAFTAR PUSTAKA}

Abdul Rouf Irwanto, 2016, Perbandingan variasi gerakan elektroda pada proses shielded metal arc welding (smaw) terhadap struktur mikro dan kekuatan bending baja Karbon rendah. Fakultas teknik: Universitas Negeri Semarang.

Awal Syahrani, 2013, variasi arus terhadap kekuatan tarik dan bending pada hasil Pengelasan SM 490. Jurnal, Fakultas Teknik: Universitas Tadulako.

Djoko Suprijanto, 2013, Pengaruh bentuk kampuh terhadap kekuatan bending las sudut Smaw posisi mendatar pada baja karbon rendah. Fakultas Teknik: Universitas Sekolah Tinggi Teknologi Nasional yogyakarta.

Evendi Sunarko, 2006, pengaruh preheated terhadap kekuatan tekan Material R.42 di daerah pengaruh panas (haz). Fakultas Teknik: Universitas Negeri Semarang.

Hadi, E.S. 2009. Analisa Pengelasan Mild Steel (ST.42) dengan Proses SMAW, FCAW dan SAW Ditinjau dari Segi Kekuatan dan Nilai Ekonomis. Kapal, Vol. 6, No. 2, Juni 2009.

Harsono W dan Toshie Okumura, 1979, Teknologi Pengelasan logam, PT Pradnya Paramitra, Jakarta.

Iham Nurdiansyah, 2016, analisis tekuk pada akar las (root bend) dan tekuk pada Permukaan las (face bend) longitudinal besi tuang kelabu pada Proses pengelasan terhadap pengujian tekuk (bending). Widya Teknika, ISSN.

Katulistiwa, I. dan Yunus. 2014. Pengaruh Variasi Besar Arus Pengelasan dan jenis Elektroda Las TIG (Tungsten Innert Gas) pada Baja Karbon Rendah Terhadap kekuatan Tarik dan Bending. JTM. Volume 02 Nomor 02.

Ruli Syahrul Furqon, 2011, pengujian dan analisis sambungan las Tabung gas lpg kapasitas $3 \mathrm{~kg}$. Fakultas Teknik: Universitas Pasunda Bandung.

Safira Dwi Anggraeni, 2016, studi perbandingan proses pengelasan smaw Pada lingkungan darat dan bawah air Terhadap ketahanan uji bending Weld joint material A36. Fakultas teknologi kelautan: Surabaya.

Syahrani, A. et al. 2013. Variasi Arus Terhadap Kekuatan Tarik dan Bending pada Hasil Pengelasan SM940. Jurnal Mekanikal, Vol.4, No. 2, Juli 2013: 393-402. 